\title{
Article
}

\section{Permanent diabetes mellitus in the first year of life}

\author{
D. Iafusco ${ }^{1}$, M. A. Stazi ${ }^{2}$, R. Cotichini ${ }^{2}$, M. Cotellessa ${ }^{3}$, M. E. Martinucci ${ }^{4}$, M. Mazzella ${ }^{3}$, V. Cherubini ${ }^{5}$, \\ F. Barbetti ${ }^{6}$, M. Martinetti ${ }^{7}$, F. Cerutti ${ }^{8}$, F. Prisco ${ }^{1}$, and the Early Onset Diabetes Study Group \\ of the Italian Society of Paediatric Endocrinology and Diabetology ${ }^{1}$
}

${ }^{1}$ Department of Paediatrics, Second University of Naples, Naples, Italy

${ }^{2}$ Department of Epidemiology - Istituto Superiore di Sanità, Rome, Italy

${ }^{3}$ Department of Paediatrics, University of Genoa, G. Gaslini Institute, Genoa, Italy

${ }^{4}$ Regional Center for Juvenile Diabetes, Meyer Paediatric Hospital, Florence, Italy

${ }^{5}$ Department of Paediatrics, University of Ancona, Ancona, Italy

${ }^{6}$ Laboratory of Molecular Endocrinology and Metabolism, IBCIT, Biomedical Scientific Park Rome S. Raffaele,

Rome and Bambino Gesù Paediatric Hospital, IRCCS, Rome, Italy

${ }^{7}$ HLA Laboratory, Immunohematology and Transfusion Center, IRCCS Policlinic, Pavia, Italy

${ }^{8}$ Department of Paediatrics, University of Turin, Turin, Italy

\section{Abstract}

Aims/hypothesis. The pathogenesis of permanent diabetes mellitus diagnosed early in life is heterogeneous and, in most cases, not known. We aimed at identifying markers differentiating between non-autoimmune and autoimmune diabetes.

Methods. The clinical, genetic and epidemiological features of 111 diabetic patients (62 males) who received insulin within 12 months of life were studied.

Results. The epidemic curve by age of diabetes onset revealed two subsets of patients at a cutoff of 180 days. In the group with diabetes onset before 180 days ("early onset" permanent diabetes) the analysis of HLA susceptibility heterodimers (available for 21 individuals) showed that $76 \%$ had a "protective" HLA genotype for Type I (insulin-dependent) diabetes mellitus as compared to $11.9 \%$ (5/42) of the later onset group. Accordingly, "early onset" children were less likely to have autoimmunity markers (4 out of 26 tested) than children with onset after 180 days (13 out 20 tested) ( $15.4 \%$ vs. $65.0 \%, p<0.01)$. Of note, 19 out of 20 (or the 95\%) patients who were born on the island of Sardinia, an Italian region where the incidence of Type I diabetes is six times higher than continental Italy (33/100000/year vs 5/100000/year), were included in the later onset group (>180 days). Small-for-date birthweight, a possible sign of reduced foetal insulin secretion, was more common in the "early onset" group $(\mathrm{OR}=9.9,95 \%$-CI 2.6-38.6).

Conclusion/interpretation. These results, obtained in the largest population-based cohort of diabetic infants hitherto reported, suggest that "early onset" permanent diabetes cases differ from later onset cases and that most of them do not have an autoimmune pathogenesis. [Diabetologia (2002) 45:798-804]

Keywords: Permanent neonatal diabetes, non-autoimmune diabetes mellitus, Type I diabetes, HLA protective heterodimers, autoimmune enteropathy
Diabetes mellitus diagnosed in the newborn or during the first few months after birth and necessitating permanent insulin treatment is a rare condition.

Because months or even years can elapse between the beginning of the autoimmune response and the clinical

Received: 2 October 2001 / Revised: 6 February 2002

Published online: 3 May 2002

(C) Springer-Verlag 2002

Corresponding author: D. Iafusco, Department of Paediatrics, Second University of Naples, Via S. Andrea delle Dame n 4 80100 Napoli, Italy, e-mail: dario.iafusco@unina2.it Abbreviations: GAD, Glutamic acid decarboxylase antibodies; EOPD, 'Early Onset' Permanent Diabetes; IPEX, immunedisregulation, polyendocrinopathy, enteropathy, $\mathrm{x}$-linked appearance of Type I (insulin-dependent) diabetes mellitus, the onset of diabetes very early in life might not be consistent with the time required for an autoimmune response to result in overt Type I diabetes mellitus, even if the autoimmune disease begins in the foetal period [1]. Neonatal diabetes with onset in the first days of life and signs of beta-cell autoimmunity has been found associated with short-term maternal enterovirus infection [2] or autoimmune entercolitis [3], but the clinical features of such cases differ from those observed in subjects with diabetes occurring later after birth, which resemble Type I diabetes. On the other hand, a few reports link non autoimmune neonatal diabetes to congenital absence of islet of Langerhans [4], extremely rare genetic disorders or syndromes [5], and pancreatic agenesis [6]. 
Within the framework of the Working Group on Diabetes of the Italian Society of Paediatric Endocrinology and Diabetology, we conducted a retrospective study to examine the clinical characteristics and laboratory findings of patients who developed permanent diabetes during the first year of life [7].

\section{Subjects and methods}

Study cohort and data collection. One hundred and eleven diabetic patients born between 1980 and 1997 who started insulin therapy in their first year of life were retrospectively identified. Data were collected by 45 Paediatric Diabetology Units which are the Italian referral centres for the diagnosis and treatment of paediatric diabetes and are located throughout Italy, thus ensuring almost complete coverage of the country. A standardised questionnaire was completed for each case: information about risk factors during pregnancy and neonatal features were collected from medical records. Data collection was completed by December 2000. Patients who developed diabetes after 1997 were excluded from the study to avoid the accidental recruitment of cases of transient neonatal diabetes.

Laboratory analyses. Data on autoimmunity markers before insulin therapy was started were available for 46/111 patients. Islet cell antibodies (ICA) were evaluated by indirect immunofluorescence using human pancreatic substrate. GAD and IA2 antibodies were evaluated by radioimmune assay. The analyses were performed in two Italian laboratories that took part in international workshops on standardisation of antibodies assays.

We were able to conduct a molecular study on 63 of the 111 patients. HLA class II $D Q B 1$ and $D Q A 1$ alleles were identified at high resolution with allele specific oligonucleotide probes or sequence specific primers and the polymerase chain reaction (PCR). An amino acid other than aspartic acid at position 57 of the $D Q \beta$ chain or an arginine at position 52 of the $D Q \alpha$ chain entail high risk for Type I diabetes susceptibility. HLA analysis was centralised.

Data analysis. "Age at onset" was the age in days upon starting insulin therapy. The epidemic curve of age at onset was smoothed by using either the moving-average technique or polynomial regressions. The standard deviation of birth weight corrected for gestational age was calculated: children under the $10^{\text {th }}$ percentile for birth weight by gestational age measured for Italian newborns [8] were defined "small for date".

Because we divided the cohort studied in two groups according to the day of onset (see below) we used Pearson $\left(\chi^{2}\right)$ chi-square or Fisher exact test to analyse frequency comparisons of qualitative variables. The proportion of exposure was calculated between the groups of patients with diabetes mellitus. The adjusted odds ratio (OR) for these variables and the effect of potential confounding variables were evaluated using unconditional logistic regression techniques.

Data were analysed using BMDP software. Ridit analysis was used to compare the distribution of susceptibility HLADQ heterodimers ( $D Q \beta 57$ NonAsp - DQ $\alpha 52 \mathrm{Arg})$ in groups of diabetic patients with the baseline distribution of susceptibility heterodimers in a sample of healthy adults [9].

\section{Results}

Epidemiological and clinical characteristics. A total of 111 diabetic patients (62 males, 49 females) born from 1980 to 1997 and who started insulin therapy in their first year of life were included in the study.

The age range at enrolment was 3.17-21.07 years. Eleven patients who had diabetes within the first month from birth and required continuous insulin therapy from the day of diagnosis met the current criteria for the diagnosis of permanent neonatal diabetes mellitus (PNDM) (see Table 1). In three of those patients diabetes was found associated to autoimmune enteropathy.

The mean incidence of diabetes in the first year of life, calculated from 1993 to 1995 , was 1.7/100000 inhabitants. Figure 1 shows the epidemic curve of the 111 patients by age at onset expressed in days. The third grade polynomial fitted to distribution had an $R^{2}$ of 0.94 , with a minimum at around 180 days. This result suggested the existence of two groups of patients based on age at onset.

Table 1 Characteristics of the eleven newborns with diabetes onset within 30 days of birth

\begin{tabular}{|c|c|c|c|c|c|c|c|}
\hline $\begin{array}{l}\text { Age at } \\
\text { onset (days) }\end{array}$ & Sex & $\begin{array}{l}\text { Year } \\
\text { of birth }\end{array}$ & $\begin{array}{l}\text { Birthweight } \\
\text { (grams) }\end{array}$ & $\begin{array}{l}\text { Gestational } \\
\text { age }\end{array}$ & $\begin{array}{l}\text { Small } \\
\text { for date }\end{array}$ & Outcome & Associated diagnosis \\
\hline 0 & $\mathrm{~F}$ & 1985 & 2300 & 40 & Yes & & Coeliac disease \\
\hline 1 & $\mathrm{~F}$ & 1992 & 1600 & 41 & Yes & & \\
\hline 1 & M & 1992 & 2440 & 41 & Yes & & \\
\hline 4 & M & 1997 & 2550 & 41 & Yes & & \\
\hline 4 & M & 1996 & 2500 & 41 & Yes & & Autoimmune enteropathy \\
\hline 15 & $\mathrm{~F}$ & 1992 & 2750 & 40 & Yes & & \\
\hline 21 & M & 1986 & 2580 & 37 & No & & \\
\hline 29 & M & 1997 & 2000 & 35 & Yes & Death & $\begin{array}{l}\text { Autoimmune enteropathy } \\
\text { ICA pos and GAD (100 U) }\end{array}$ \\
\hline
\end{tabular}

ICA, islet cell antibodies; GAD, glutamic acid decarboxylase antibodies 


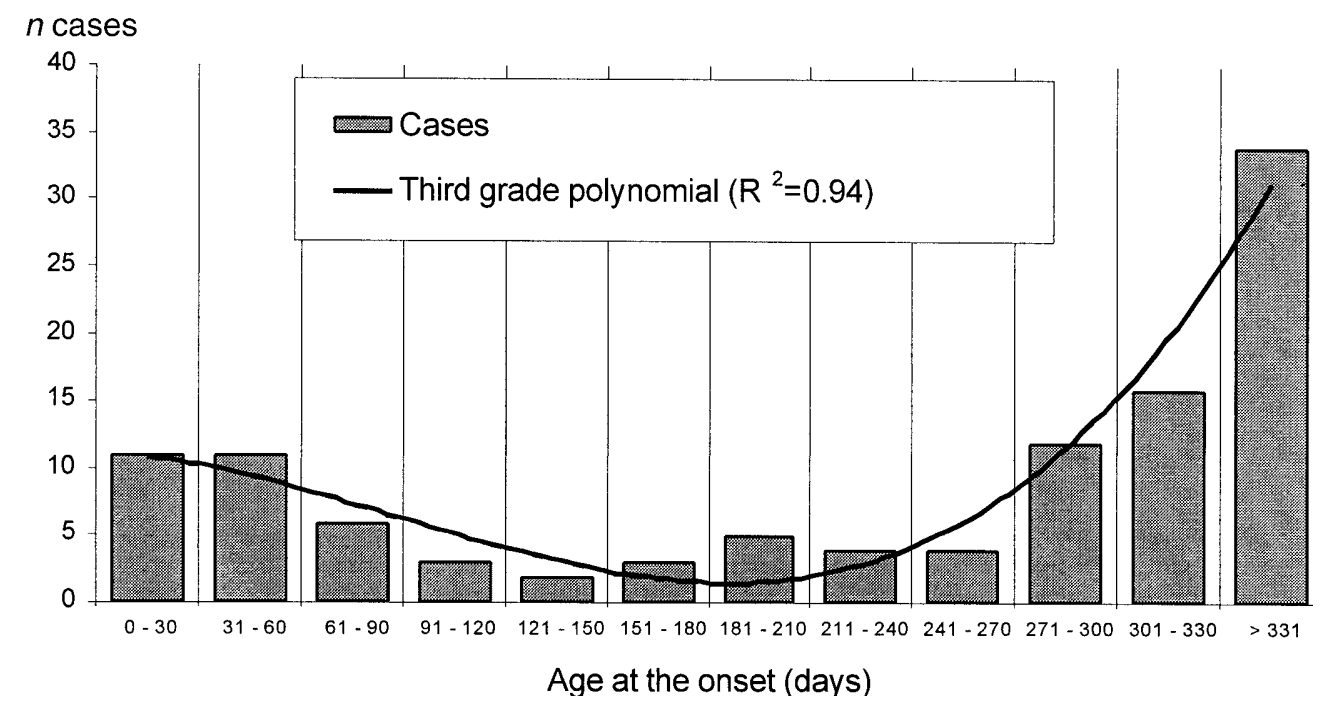

Fig. 1 Frequency distribution of age at onset (in days) of 111 diabetic children diagnosed within the first year of life (Italy, 1980-1997)

Consequently, the 36 children diagnosed within the first 6 months of life (herein defined "early onset" permanent diabetes, EOPD ) were compared with the 75 children diagnosed between months $7-12$ of life. The clinical and epidemiological characteristics of the two groups are shown in Table 2 .

In an attempt to determine whether diagnostic procedures and survival differed over time, we divided the two groups into four 5-year periods. There were no differences between or within the two groups.

The percentages of threatened abortions was higher in mothers of children with EOPD than in mothers of children diagnosed later $(52.2 \%$ vs $20.0 \%, p=0.01)$. The proportion of children born before 37 weeks gestational age was higher in the EOPD group (15.4\% vs $2.7 \%, p=0.06$ ); a birth weight lower than $2500 \mathrm{~g}$ was clearly associated with EOPD (40.7\% vs $4.7 \%$, $p=0.001)$. Small-for-date birth weight was more common in the EOPD group (64.3\% vs $14.3 \%, p=0.001)$.

One of the 36 children with "early onset" permanent diabetes and 19 of the 75 with a later diabetes diagnosis were born in Sardinia $(p=0.004)$.

Table 2 reports also the results of the unconditional logistic regression. In the multivariate analysis, three variables were significantly associated with the EOPD: threaten abort $(\mathrm{OR}=5.4)$, small for date $(\mathrm{OR}=9.9)$ and "born outside Sardinia" $(\mathrm{OR}=10.1)$.

HLA genotype. Altogether 16 of the 21 EOPD patients tested carried a "protective" HLA genotype for autoimmune diabetes: of those, 11 did not bear any susceptibility heterodimers and five had only one susceptibility heterodimer $(\mathrm{OR}=0.04,95 \%$ CI $0.01-0.60)$ (Table 3 ). In contrast, only five of the 42 genotyped

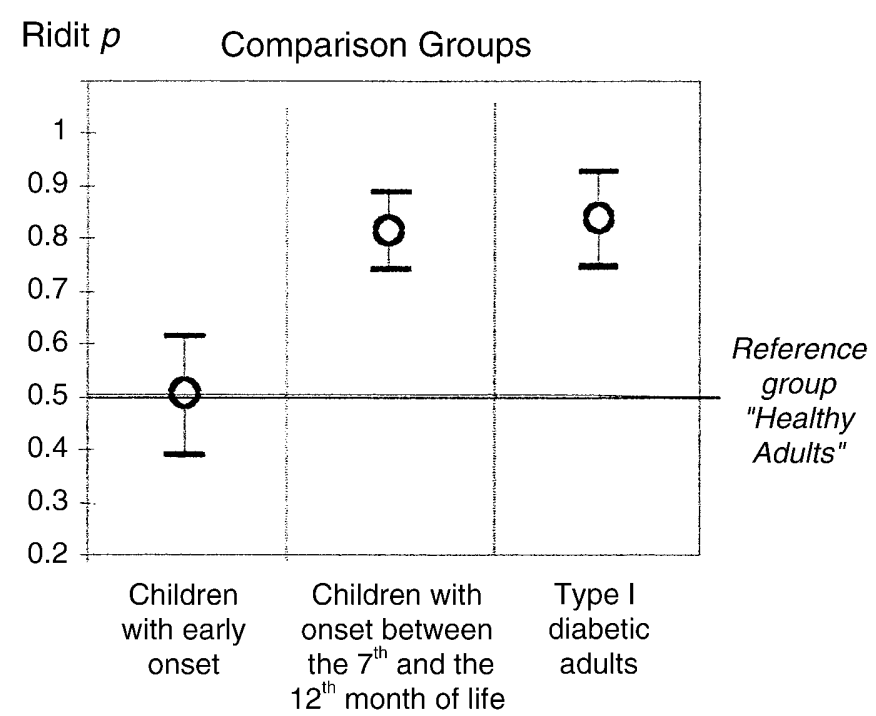

Fig. 2 Ridit values and their 95\%-Confidence intervals for HLA DQ susceptibility heterodimers in three groups of diabetic patients compared with a sample of healthy subjects. A ridit analysis is the estimated probability that random individual from a comparison group is "to the right" of a person selected at random from the reference group. In this case, two groups are different from the reference group (ridit $=0.5$ ). Individuals in these groups are likely to have more susceptibility heterodimers than healthy subjects (reference group); the "early onset" permanent diabetes group do not appear to differ from the reference group

patients with diabetes onset between 180 and 365 days of life carried a "protective" HLA genotype: two patients without susceptibility heterodimers, and three patients with one susceptibility heterodimer.

Table 3 also shows the frequency distribution of susceptibility heterodimers in our study population (divided into "early onset" and onset between months 7-12 of life). These data are compared with those obtained in healthy adults and patients with Type I diabetes from an Italian case-control study [9]. Figure 2 shows the results of ridit analysis of the number of sus- 
Table 2 Frequency distribution and adjusted odds ratios (OR) with $95 \%$ Confidence intervals of selected characteristics for diabetes diagnosed during the first 6 months of life ("early on- set" permanent diabetes) compared with diabetes beginning between the $7^{\text {th }}$ and the $12^{\text {th }}$ month of life. The adjusted OR was reported for the variables that entered in the multivariate model

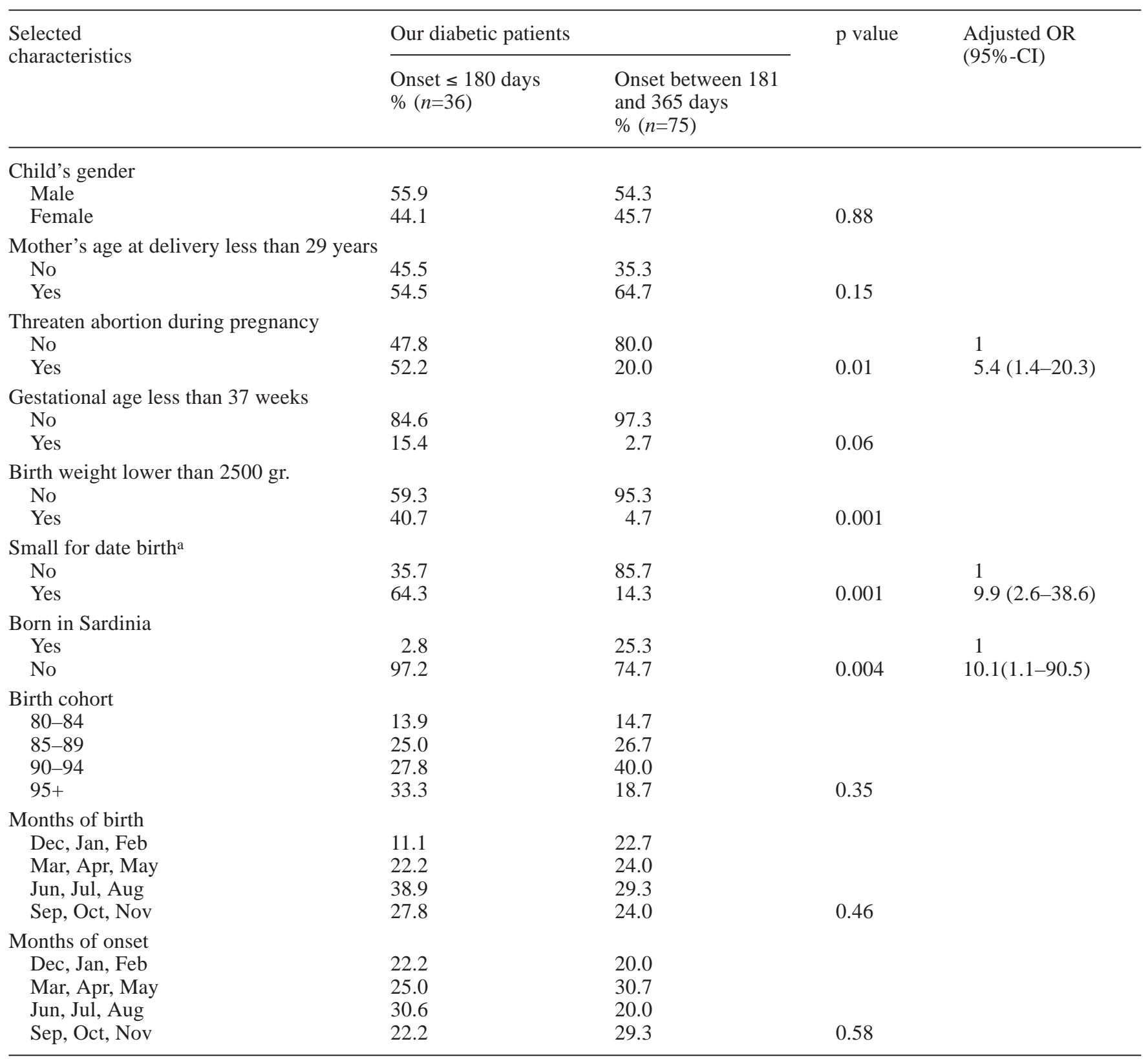

a This variable is a function of child's gender, gestational age and birth weight

ceptibility heterodimers in the same groups. Children with diabetes onset between 181 and 365 days of life and patients with Type I diabetes differ from healthy adults (reference category) and do not appear to differ from each other. Children with diabetes onset before 180 days do not differ from the healthy adults category of the reference (ridit $p=0.51,95 \%$-CI 0.30-0.72) [9].

Therefore, children diagnosed after the sixth month of life have an HLA-DQA1 and DQB1 genotype distribution similar to Type I diabetic patients, whereas "early onset" children are similar to healthy adults [9]. Of note, the EOPD group had an increased frequency of the haplotype HLA-DQA1*0102, DQB1*0602: $11.9 \%$ vs $2.2 \%$ of patients with diabetes onset from months $7-12$ of life $\left(p_{\text {corr }}=0.04 ; \mathrm{OR}=5.54\right)$, compared with $3.1 \%$ of patients with Type I diabetes [9] ( $\left.p_{\text {corr }}=0.04 ; \mathrm{OR}=4.26\right)$ and vs $5.4 \%$ of adult controls [9] $\left(p_{\text {corr }}=\mathrm{ns} ; \mathrm{OR}=2.38\right)$.

Markers of autoimmunity. Children in the EOPD group (26/36 tested) were less likely to result positive to any of these tests as compared with children with onset of diabetes after 180 days (20/75 tested) $(4 / 26=15.38 \%$ vs $13 / 20=65 \%, p<0.001)$. 
Table 3 HLA-DQ $\alpha$ (position 52) and HLA-DQ $\beta$ (position 57) susceptibility heterodimers: comparison between our study population, healthy subjects [9] and patients with Type I diabetes [9]

\begin{tabular}{|c|c|c|c|c|c|c|c|c|}
\hline \multirow[t]{4}{*}{$\begin{array}{l}\text { Number of susceptibility } \\
\text { heterodimers }\end{array}$} & \multicolumn{4}{|c|}{$\begin{array}{l}\text { Children with permanent diabetes } \\
\text { (Our study population) }\end{array}$} & \multicolumn{4}{|c|}{ Type I diabetes case-control study [9] } \\
\hline & \multicolumn{2}{|c|}{ Onset $\leq 180$ days } & \multicolumn{2}{|c|}{$\begin{array}{l}\text { Onset between } 181 \\
\text { and } 365 \text { days }\end{array}$} & \multicolumn{2}{|c|}{$\begin{array}{l}\text { Patients with } \\
\text { Type I diabetes }\end{array}$} & \multicolumn{2}{|c|}{ Healthy adults } \\
\hline & \multirow[t]{2}{*}{$n$} & \multirow[t]{2}{*}{$\%$} & & & & & \multirow{2}{*}{$n$} & \multirow[t]{2}{*}{$\%$} \\
\hline & & & $n$ & $\%$ & $n$ & $\%$ & & \\
\hline 4 & 1 & 4.8 & 17 & 40.5 & 23 & 35.4 & 1 & 1.1 \\
\hline 2 & 4 & 19.0 & 20 & 47.6 & 27 & 41.5 & 20 & 21.5 \\
\hline 1 & 5 & 23.8 & 3 & 7.1 & 8 & 12.3 & 23 & 24.7 \\
\hline 0 & 11 & 52.4 & 2 & 4.8 & 7 & 10.7 & 49 & 52.7 \\
\hline Total & 21 & & 42 & & 65 & & 93 & \\
\hline
\end{tabular}

\section{Discussion}

We have confirmed with this investigation, that the incidence of diabetes during the first year of life is low. Our data indicate that the mean incidence, estimated between 1993 and 1995, was in fact 1.7/100000, a figure comparable to the one estimated in Germany in 1993 and in 1995 (1.43 and 1.96/100000, respectively) [10]. However, the most striking result of this study is the clear separation of patients with onset of diabetes before and after 180 days of life in two distinct groups (third grade polynomial fitted to distribution: $\left.R^{2}=0.94\right)$. We thus looked for differences between these two populations. An immediate observation was that the presence of genetic markers of susceptibility to Type I diabetes (DQ $\beta / D Q \alpha$ NonAsp/Arg heterodimers) in individuals from the "early onset" group was similar to that of the general population. In contrast, predisposing heterodimers in patients diagnosed after 180 days of life were found in a percentage as high as that found in Italian patients affected by Type I diabetes [9]. These data are even more relevant if we consider that Type I diabetic patients diagnosed in childhood are more likely than adults to carry HLA alleles associated with disease susceptibility $[11,12]$ and, in addition, in very young children diabetes appears to be associated with a higher-risk genotype than in older children [13].

Furthermore, the EOPD group is similar to the control cohort [9] for all but one HLA-DQA1,DQB1 haplotype frequencies, the only deviation being confined to HLA-DQA1*0102,DQB1*0602 haplotype whose frequency was $11.9 \%$ in EOPD patients vs $5.4 \%$ of controls [9], 3.1\% of Type I diabetic patients [9] and $2.2 \%$ of babies with diabetes onset between 181 and 365 days. This haplotype has been claimed to confer protection against autoimmune diabetes carrying a double protection at the amino acid residues of DQ $\alpha$ and DQ $\beta$ chains [14].

Relevant to this issue was also the observation that in 35 out of 36 Sardinian patients of our collection the onset of diabetes was after the 180th day, when the likelihood of autoimmune diabetes is higher. This is in keeping with the peculiar distribution of Type I diabetes in Italy where the incidence in the continental part of the country (between 3.5 and 7/100000/year, similar to the rest of Europe) is much lower than the one observed in the island of Sardinia, a 33/100000/year that represents the highest in the Mediterranean area. On the same token only four patients of the EOPD group tested positive for one or more antibodies of Type I diabetes among the 26 in which the serological markers were available. Of note, among these four one male had also autoimmune enteropathy.

Recently, mutations of the FOXP3 gene have been identified in patients with $\mathrm{X}$-linked neonatal diabetes, enteropathy and polyendocrinopathy (IPEX syndrome) $[15,16]$ and it is very likely that the three males of the EOPD group (diagnosed at the ages of 4, 29 and 31 days in which neonatal diabetes was associated to a severe autoimmune enteropathy from which two of them died, could have borne a FOXP3 mutation.

Duration of pregnancy and birthweight. We found that birth weight and duration of pregnancy are both different in patients with EOPD compared with patients with onset of diabetes after 180 days from birth. The likelihood of a gestational age of less than 37 weeks was higher in the EOPD group (15.4\% vs $2.7 \%$ ).

Furthermore, according to the multivariate analysis results, a 'small-for-date' newborn has an almost tenfold increase in risk of developing EOPD. A low birth weight could indicate a reduced or absent insulin secretion by the foetal pancreas, such as in individuals with pancreatic agenesis due to homozygous mutation of IPF1/MODY 4 [6], or heterozygous mutations of the glucose sensor glucokinase (GK/MODY 2) [17, $18,19]$. In keeping with this assumption, we found a homozygous mutation of the GK/MODY2 in one of the patients reported here, with diabetes onset on the first day of life and a birth weight of $1600 \mathrm{~g}$ [20]. 
Thus, even though we do not exclude the possibility of cases of autoimmune diabetes in very young infants, this seems to be a quite rare event in isolation. Diabetes with autoimmune phenomena is instead connected to complex syndrome(s) $[3,15,16]$, sometimes associated to the presence of higher concentrations of autoimmune markers or histological evidence of insulitis [21] or both, or to viral infections [2].

In conclusion, the group of patients with diabetes onset before 180 days of life is likely characterised by form(s) of diabetes other than Type I, which instead seems to be more prevalent in patients with onset after 180 days.

This concept is in agreement with the findings [22] of a prospective study aimed at identifying autoimmune markers of Type I diabetes in subjects who successively developed diabetes, did not find antibodies before the first six months of life.

Moreover, patients with autoimmune markers at birth who later became diabetic, never had a clinical onset of diabetes before 3.3 years of age and, generally, later [1].

This study illustrates the importance of investigating patients affected by diabetes mellitus in the first months of life. In fact, although such cases are rare, they represent a useful model that might help to clarify the causes of non-Type I forms of diabetes, which can be caused by defects of genes important in embryonic pancreas development [6] or glucose-induced insulin secretion [20].

Acknowledgements. Co-authors are the members of the Early Onset Diabetes Study Group of the Italian Society of Paediatric Endocrinology and Diabetology. A.R. Fifi (Arezzo), L. Cavallo (Bari), E. Frezza, E. Piccinno (Bari), A. Vergerio (Feltre BL), E. Cacciari, S. Salardi (Bologna), E. Angius, P. Frongia (Cagliari), C. Pintor (Cagliari), A. La Loggia (Caltanissetta), M. Cicchetti (Campobasso), G. Reitano, M. Mancuso (Catania), M. Pocecco, G. Cerasoli (Cesena), F. Chiarelli, A. Verrotti (Chieti), R. Vanini, L. Spallino (Como), A. Vaccà (Cosenza), P. Banin (Ferrara), S. Toni (Firenze), C. Mastrangelo (Foggia), R.Lorini, I Bertini (Genova), P. Picco (Genova), A. Monaci (Grosseto), F. De Luca, F. Lombardo (Messina), G. Chiumello, F. Meschi (Milano), S. Bernasconi, L. Iughetti (Modena), A. Franzese (Napoli), O. Stoppoloni (Napoli), G. Bona, F. Cadario (Novara), A. Milia (Nuoro), L. Bellu (Olbia), C. Monciotti (Padova), F. Cardella (Palermo), M. Vanelli, G. Chiari (Parma), G.D'Annunzio (Pavia), G. De Giorgi (Perugia), L. Calisti (Pisa), G. Zanette (Pordenone), E. Bartolotta, L. Guazzarotti (Recanati), A. Crinò (Roma), L. Lucentini, I.P. Patera (Roma),G. Marietti, ML Manca Bitti (Roma), G. Multari, N. Sulli (Roma), A.M. Marinaro, A. Ogana (Sassari), A. Falorni (Terni), I. Rabbone (Torino), V. Cauvin (Trento), A. Visentin (Treviso), G. Tonini, E.Buratti (Trieste), P. Salvatoni (Varese), L. Pinelli (Verona). We are grateful to I. Bertini and L. Minicucci for HLA-typing and J. A. Gilder for text editing.

\section{References}

1. Lindberg B, Ivarsson SA, Landing-Olsson M, Sundkvist G, Svanberg L, Lernmark A (1999) Islet autoantibodies in cord blood from children who developed Type I (insulin dependent) diabetes mellitus before 15 years of age. Diabetologia 42:181-187

2. Otonkoski T, Roivainen M, Vaarala O et al. (2000) Neonatal Type I diabetes associated with maternal echovirus 6 infection: a case report. Diabetologia 43:1235-1238

3. Mazzella M, Bellini C, Bertini IM, Massocco DS, Cotellessa M, Serra G (2001) Evidence of autoimmunity in male twins with neonatal diabetes. Diabetes Care 24:408

4. Dodge JA, Lawrence KM (1977) Congenital absence of islet of Langerhans. Arch Dis Child 52:411-413

5. Superti-Furga A, Schoenle E, Tuchschmid P et al. (1993) Pearson bone marrow-pancreas syndrome with insulindependent diabetes, progressive renal tubulopathy, organic aciduria and elevated fetal haemoglobin caused by deletion and duplication of mitochondrial DNA. Eur J Pediatr 152:44-50

6. Stoffers DA, Zinkin NT, Stanojevic V, Clarke WL, Habener JF (1997) Pancreatic agenesis attributable to a single nucleotide deletion in the human IPF1 gene coding sequence. Nat Genet 15:106-110

7. Iafusco D, Cotellessa M, Cerutti F et al. (1998) Study on epidemiology and clinic of early onset diabetes. Riv Ital Pediatr 24:163-167

8. Parazzini F, Cortinovis I, Bortolus R, Fedele L, Decarli A (1995) Weight at birth by gestational age in Italy. Human Reprod 10:1862-1863

9. Buzzetti R, Nisticò L, Osborn JF, Giovannini C, Chersi A, Sorrentino R. (1993) HLA-DQA1 and DQB1 gene polymorphisms in Type I diabetic patients from central Italy and their use for risk prediction. Diabetes 42:1173-1178

10. Rosenbauer J, Herzig P, von Kries R, Neu A, Giani G (1999) Temporal, seasonal, and geographical incidence patterns of Type I diabetes mellitus in children under 5 years of age in Germany. Diabetologia 42:1055-1059

11. Caillat-Zucman S (1992) Age-dependent HLA genetic heterogeneity of Type I insulin-dependent diabetes mellitus. J Clin Invest 90:2242-2250

12. Shield J, Wadsworth E, Baum JD (1995) The genetic contribution to disease pathogenesis in childhood diabetes is greatest in the very young. Diabet Med 12:377-379

13. Komulainen J, Kulmala P, Savola K et al. The Childhood Diabetes in Finland (DiMe) Study Group (1999) Clinical, autoimmune, and genetic characteristics of very young children with Type I diabetes. Diabetes Care 22:1950-1955

14. Schipper RF, Koeleman BP, Bruining GJ et al. (2001) HLA class II associations with Type 1 diabetes mellitus: a multivariate approach. Tissue Antigens 57:144-150

15. Wildin RS, Ramsdell F, Peake J et al. (2001) X-linked neonatal diabetes mellitus, enteropathy and endocrinopathy syndrome is the human equivalent of mouse scurfy. Nat Genet 27:18-20

16. Bennet CL, Christie J, Ramsdell F et al. (2001) The immune dysregulation, polyendocrinopathy, enteropathy, Xlinked syndrome (IPEX) is caused by mutations of FOXP3. Nat Genet 27:20-21

17. Hattersley A T, Beards F, Ballantyne E, Appleton M, Harvey R, Ellard S (1998) Mutations in the glucokinase gene of the fetus result in reduced birth weight. Nat Genet 19:268-270

18. Hattersley AT, Tooke JE (1999) The fetal insulin hypothesis: an alternative explanation of the association of low birthweight with diabetes and vascular disease. Lancet 353:1789-1792 
19. Prisco F, Iafusco D, Franzese A, Sulli N, Barbetti F (2000) MODY 2 presenting as neonatal hyperglycaemia: a need to reshape the definition of "neonatal diabetes"? Diabetologia $12: 1331$

20. Njolstad PR, Sovik O, Cuesta-Munoz A et al. (2001) Neonatal diabetes mellitus due to complete glucokinase deficiency. N Engl J Med 344:1588-1592

21. Cilio CM, Bosco A, Moretti C et al. (2000) Congenital autoimmune diabetes mellitus. N Engl J Med 342:1529-1531
22. Ziegler AG, Hummel M, Schenker M, Bonifacio E (1999) Autoantibody appearance and risk for development of childhood diabetes in offspring of parents with Type I diabetes. The 2-year analysis of the German BABYDIAB study. Diabetes 48:460-468

23. Iafusco D, Prisco F, Stoppoloni O, Accolla RS, Tosi G (1999) HLA-DQ. Genotype in early onset insulin dependent diabetes mellitus. J Pediatric Endocrinol Metabol 12:887-890 